\title{
PENGEMBANGAN LEMBAR KERJA MAHASISWA BERBASIS POE DAN KEMAMPUAN BERPIKIR KRITIS MAHASISWA PADA TOPIK FLUIDA STATIS
}

\author{
Muhammad Reyza Arief Taqwa ${ }^{1 *}$, Revnika Faizah ${ }^{2}$, Lugy Rivaldo ${ }^{3}$ \\ ${ }^{1}$ Program Studi Pendidikan Fisika, FMIPA, Universitas Negeri Malang, Malang, Indonesia \\ ${ }^{2}$ Pasca Sarjana, Pendidikan Fisika, Universitas Negeri Yogyakarta, Yogyakarta, Indonesia \\ ${ }^{3}$ Program Studi Pendidikan Fisika, FKIP, Universitas Jambi, Muaro Jambi, Indonesia \\ Email: reyza.arief.fmipa@um.ac.id*, revnikaf@gmail.com, lugyrivaldo@unja.ac.id
}

\section{Info Artikel}

Diterima:

4 Februari 2019

Disetujui:

8 Mei 2019

Dipublikasikan:

30 Juni 2019

\begin{abstract}
Abstrak:
Telah dikembangkan Lembar Kerja Mahasiswa (LKM) berbasis Prediction, Observation, and Explanation (POE) pada topik fluida statis. Artikel ini bertujuan untuk mendiskripsikan validasi LKM berbasis POE, mendiskripsikan respon, dan mendiskrisikan kemampuan berpikir kritis mahasiswa setelah menggunakan LKM berbasis POE. Pengembangan ini menggunakan model pengembangan ADDIE. LKM telah divalidasi dan dilakukan uji terbatas kepada beberapa mahasiswa. Setelah dilakukan revisi, uji coba terbatas dilakukan kepada 25 mahasiswa S1 Pendidikan Fisika pada perkuliahan Fisika Dasar I. Kemampuan berpikir kritis mahasiswa diperoleh dari tes. Informasi kemampuan berpikir kritis mahasiswa diperoleh dari perolehan skor untuk tiap indikator. Dari analisis yang di dapat, seluruh indikator memperoleh hasil validasi ahli dengan kategori sangat valid. Mahasiswa secara keseluruhan memberikan respon positif terhadap produk dan kemampuan berpikir kritis secara keseluruhan sebesar $69,60 \%$ sehingga dapat disimpulkan bahwa kemampuan berpikir mahasiswa berada pada kategori kritis.
\end{abstract}

Kata kunci: lembar kerja mahasiswa, POE, fluida statis

\begin{abstract}
:
Students Worksheet based on Prediction, Observation, and Explanation (POE) have been developed on statistical fluid topics. This article aims to describe the validation of Students Worksheet base on POE, describe responses, and discern students' critical thinking skills after using Students Worksheet based on POE. This development uses the ADDIE development model. The Students Worksheet has been validated and limited trials to several students. After revision, limited trials were conducted on 25 undergraduate students of Physics Education in Basic Physics I. The students' critical thinking skills were obtained from the test. Information on students' critical thinking skills is obtained from the acquisition of scores for each indicator. From the analysis that can be used, the results of expert validation in all indicators are very valid. Students as a whole give a positive response to the product and the critical thinking ability sekor is $69.60 \%$ so we can conclude that students' thinking skills are in the critical category.
\end{abstract}

Keywords: students worksheet, POE, static fluida 


\section{Pendahuluan}

Fisika merupakan pengetahuan alam yang berguna untuk menjelaskan bermacam fenomena dan menjadi dasar untuk memecahkan permasalahan fisis, sehingga pemahaman konsep fisika oleh peserta didik harus memadai (Taqwa et al, 2017). Untuk mencapai hal tersebut dilakukan dengan serangkaian kegiatan ilmiah seperti melakukan kegiatan observasi, membuat hipotesis, melakukan kegiatan eksperimen, menganalisis data yang diperoleh, sampai kepada menyampaikan temuan. Dalam kegiatan pembelajaran peserta didik dituntut untuk aktif mencari pengetahuannya sendiri melalui kegiatan ilmiah sebagai mana ilmuan bekerja.

Kontras dengan hal itu, sering kali pembelajaran fisika seolah-olah hanya kegiatan transfer informasi dari guru/dosen kepada siswa/mahasiswa. Jika hal tersebut terjadi maka siswa/mahasiswa cenderung menghapal pengetahuan apa yang mereka peroleh dari guru/dosennya (Rahmat et al, 2014). Sejatinya, pembelajaran fisika tidak hanya sebatas mencapai goal dalam hal mentransfer fakta, konsep, prinsip, maupun hukum semata, melainkan siswa/mahasiswa diharapkan agar dapat menguasai seluruhnya melalui proses penemuan (Anggraini et al, 2016). Dengan tuntutan demikian, pembelajaran tidak lagi terpusat pada guru dan siswa/mahasiswa bukan sekedar individu pasif yang menerima informasi dari yang diberikan.

Kendati siswa/mahasiswa harus berperan aktif, namun peranan guru/dosen dalam mengarahkan proses pembelajaran juga penting. Salah satu upaya yang dapat dilakukan adalah dengan menyusun Lembar Kerja Mahasiswa (LKM) untuk panduan proses pembelajaran mahasiswa. Sama halnya dengan panduan untuk belajar siswa (Lembar Kerja Siswa atau LKS), LKM merupakan lembaranlembaran yang berisikan tugas yang harus dikerjakan oleh peserta didik secara mandiri maupun berkelompok agar mereka dapat memperoleh pengetahuan maupun keterampilan yang harus dikuasai oleh mereka (Fitriyati et al, 2013). Penggunaan LKM dalam perkuliahan ini sesuai dengan hakikat pembelajaran fisika yang mengacu pada proses, bukan sekedar hasil akhir atau produk semata (Maharani et al, 2015).
Berdasarkan pada analisis kebutuhan yang dilakukan melalui wawancara, mahasiswa cenderung menginginkan pembelajaran yang lebih bervariasi, tidak hanya sekedar pembelajaran yang dilakukan dengan metode ceramah. Selain membosankan, jika pembelajaran yang hanya sekedar menggunakan metode ceramah maka topik yang disampaikan akan lebih cepat lupa (Miswadi et al, 2010). LKM berbasis POE dikembangkan untuk mampu mengajak mahasiswa lebih aktif dan mampu berlatih untuk dapat berpikit kritis. Melatih mahasiswa untuk berpikir kritis ini penting karena melalui berpikir kritis, siswa dilatih untuk mengamati keadaan, memunculkan pertanyaan, merumuskan hipotesis, mengumpulkan data dan kemudian mengenalisis hingga menarik kesimpulan (Wahyuni, 2015). Berpikir kritis dapat diartikan sebagai kemampuan dalam menganalisis ide maupun gagasan menuju kepada arah yang lebih spesifik; membedakan secara tajam; memilih, mengidentifikasi, mengkaji, dan mengembangkannya ke arah yang lebih baik.

Kemampuan berpikir kritis mahasiswa sangat beragam, bergantung pada kempuan kognitif berdasarkan pengalaman belajar yang diperoleh sebelumnya. Selain itu, kemampuan berpikir kritis juga dipengaruhi oleh intensitas latihan mahasiswa untuk mengembangkan kemampuan berpikir kritis (Anggraini et al, 2017). Berpikir kritis ini penting untuk dilatih untuk mempersiapkan lulusan agar siap bersaing dalam mengisi pasar kerja, karena mengingat tantangan kedepan yang semakin berat dalam menghadapi Masyarakat Ekonomi ASEAN (MEA) (Nurhudayah et al, 2016). Pada topik fisika, khususnya topik fluida statis merupakan salah satu topik yang penting untuk mendapat perhatian penelitian.

Fluida statis merupakan hal yang dapat dengan mudah dijumpai dalam kehidupan sehari-hari. Hal tersebut justru membuat mahasiswa datang ke kelas dengan pengetahuan yang mereka bangun sendiri dari mengamati fenomena di sekeliling mereka (Başer, 2006; Clement, 1982; Docktor \& Mestre, 2014; Minogue \& Borland, 2016). Peserta didik sering kali membangun pengetahuan sendiri dari pengamatan yang mereka alami sendiri dan pengetahuan yang mereka bangun sendiri tersebut lebih dipercaya, namun sayangnya pengetahuan tersebut sering kali keliru atau 
tidak sesuai secara ilmiah (Rivaldo et al, 2018). Hal tersebut menyebabkan kekeliruan dalam memahami konsep ini cenderung sulit untuk dirubah (Taqwa et al, 2019) dan siswa justru sering kali menggunakan pengetahuan keliru dan tidak relevan tersebut untuk memecahkan suatu persoalan (Taqwa \& Faizah, 2016).

Dalam artikel ini akan dibahas mengenai hasil pengembangan LKM berbasis POE. Pengembangan LKM berbasis POE bertujuan untuk memfasilitasi mahasiswa belajar dengan cara mengonstruk pengetahuan secara mandiri. Dengan integrasi POE, mahasiswa dapat belajar dengan lebih menyenangkan dan berkualitas (Hidayah \& Yuberti, 2018). Selain itu, implementasi media pembelajaran berbasis POE ini menggiring mahasiswa untuk memahami fisika secara lebih bermakna. Diharapkan dengan implementasi LKM berbasis POE ini pengetahuan mahasiswa tidak dalam bentuk resource (Hammer, 1996, 2000; Rivaldo et al, 2018; Taqwa \& Pilendia, 2018; Taqwa et al, 2017), namun menjadi body of knowledge yang koheren. Dengan POE pula siswa dapat mempertajam keterampilan proses sains (Rozana et al, 2018). Hal tersebut bermuara pada peningkatan kemampuan berpikir kritis siswa (Marcella et al, 2018). Oleh karenanya, penyusunan dan implementasi LKM dengan mengintegrasikan POE dapat dijadikan upaya untuk memperbaiki proses dan hasil pembelajaran fisika.

\section{Metode Penelitian}

Penelitian yang dilakukan adalah penelitian pengembangan yang bertujuan untuk menghasilkan inovasi produk bahan ajar berupa lembar kerja mahasiswa pada perkuliahan Fisika Dasar 1 untuk melatih berpikir kritis mahasiswa. Desain penelitian yang digunakan adalah model pengembangan ADDIE (Aldobie, 2015; Fitriastuti et al, 2018). Model ADDIE dibagi ke dalam 5 fase, yaitu: 1) Analisi (Analyze), 2) Perencanaan (Design), 3) Pengembangan (Development), 4) Implemntasi (Implementation), 5) Evaluasi (Evaluation). Pada tahap pertama, kegiatan analisis dilakukan untuk mengkaji fakta lapangan. Hal tersebut berguna untuk menganalisis kebutuhan pengembangan, melihat kekuatan dan kelemahan untuk memaksimalkan produk yang akan dikembangkan. Pada tahap kedua, berdasarkan analisis awal yang telah dilakukan kemudian dilakukan rancangan awal LKM berbasis POE. Setelah selesai dikembangkan, pada tahap kedua produk awal dilakukan koreksi oleh tim ahli. Berdasarkan hasil expert judgement tersebut dilakukan perbaikanperbaikan untuk menyempurnakan produk. Setelah direvisi, pada tahap ketiga LKM berbasis POE ini dilakukan uji terbatas sekaligus implementasi awal. Pada tahap ini, produk diimplementasikan pada pengguna terbatas dan kemudian dinilai menurut pandangan pengguna. Berdasarkan penilaian dan implementasi tersebut, kemudian dilakukan evaluasi untuk melakukan perbaikan-perbaikan untuk penyempurnaan produk.

Subjek penelitian ini adalah Mahasiswa yang sedang menjalani perkuliahan Fisika Dasar 1 sebanyak 25 mahasiswa. Teknik pengumpulan data untuk validasi menggunakan lembar validasi. Respon siswa pengumpulan data menggunakan angket respon dan kemampuan berpikir kritis menggunakan tes.

Teknik analisis data yang dilakukan untuk mengetahui tingkat validitas LKM yang dikembangkan adalah sebagai berikut (Akbar, 2013).

- Menghitung nilai validasi LKM yang diperoleh dari hasil penilaian validator, yakni dengan menggunakan persamaan:

$V_{a h}=\frac{T S_{e}}{T S_{h}} \times 100 \%$

- Menghitung nilai validasi LKM yang diperoleh dari pengguna (uji terbatas) dengan menggunakan persamaan:

$$
V_{p g}=\frac{T S_{e}}{T S_{h}} \times 100 \%
$$

Untuk mengetahui respon mahasiswa terhadap LKM berbasis POE yang telah dikembangkan dianalisis dengan menggunakan persamaan berikut (Bakri et al, 2015).

$$
\text { PRS }=\frac{\sum S P}{\sum S M} x 100 \%
$$

Keterangan:

PRS : persentase respon siswa (mahasiswa)

SP : skor perolehan

SM : skor maksimum

Dalam penelitian ini, dilihat kemampuan berpikir kritis mahasiswa setelah menggunakan Lembar Kerja Mahasiswa faqwa, Lugy Rivaldo, Revnika Faizah) hal:6-13 
berbasis POE. Kemampuan berpikir kritis mahasiswa diperoleh dari tes. Analisis data dilakukan melalui rekapitulasi hasil tes kemampuan berpikir kritis yang diperoleh dengan mencakup seluruh indikator kemampuan berpikir kritis. Setelah itu menentukan persentase skor pada tiap indikator.

\section{Hasil Penelitian dan Pembahasan}

Kelayakan Produk Lembar Kerja Mahasiswa Berbasis POE

Lembar kerja mahasiswa yang dikembangkan ini terlebih dahulu divalidasi oleh 3 dosen pendidikan fisika dan dilakukan uji terbatas pada 25 mahasiswa untuk melihat kebergunaan produk yang dikembangkan. Adapun aspek-aspek yang divalidasi pada lembar kerja mahasiswa ini antara lain adalah (1) kesesuaian konsep fisis; (2) kelengkapan pembahasan dan keutuhan konsep; (3) kesesuaian LKM dengan tuntutan pembelajaran yang terpusat pada siswa; (4) penggunaan bahasa yang baik; dan (5) cara penyajian yang baik. Tiap-tiap aspek yang dinilai dikembangkan kembali menjadi beberapa indikator. Hasil rata-rata skor yang diberikan oleh validator untuk tiap aspek ditunjukkan Tabel 1.

Tabel 1. Hasil Validasi Ahli

\begin{tabular}{llll}
\hline No. & Aspek & Rata-Rata Skor & Kategori \\
\hline 1. & Kesesuaian konsep fisis & 3,83 & Sangat valid \\
2. & $\begin{array}{l}\text { Kelengkapan pembahasan dan keutuhan } \\
\text { konsep }\end{array}$ & 3,67 & Sangat valid \\
3. & $\begin{array}{l}\text { Kesesuaian LKM dengan tuntutan } \\
\text { pembelajaran yang terpusat pada siswa }\end{array}$ & 3,67 & Sangat valid \\
4. & Penggunaan bahasa yang baik & 3,50 & \\
5. & Cara penyajian yang baik & 3,67 & Sangat valid \\
\hline
\end{tabular}

Berdasarkan Tabel 1 tampak bahwa lembar kerja mahasiswa yang dikembangkan sangat valid menurut ketiga validator. Validitas dalam pengembangan lembar kerja mahasiswa ini menekankan pada validitas isi dan validitas konstruk. Validitasi isi dalam pengembangan ini menyatakan bahwa bahan ajar yang dikembangkan telah sesuai dengan materi yang seharusnya diajarkan. Untuk menguji validitas konstruk atau construct validity maka dapat digunakan pendapat ahli (judgment validity) (Riduwan, 2008).

Berdasarkan hasil validasi lembar kerja mahasiswa berbasis POE, dari 2 aspek pada kesesuaian konsep, dinilai memiliki rata-rata skor validitas pada kriteria sangat valid. Hal ini menunjukkan bahwa lembar kerja mahasiswa bebasis POE sudah sesuai dengan standar yang harus dicapai dalam perkuliahan. Selain itu, pembelajaran ilmu alam, khususnya fisika menuntut agar mahasiswa berperan aktif selama proses pembelajara. Sehingga dalam pengembangan bahan ajar juga sedemikian menggiring mahasiswa agar berperan aktif dalam kegiatan pembelajaran. Menurut validator berdasarkan aspek tersebut lembar kerja mahasiswa berbasis POE ini sudah sangat valid yakni dengan rata-rata skor 3,67. Selain dari faktor kesuaian materi dan tuntutan pembelajaran, hadirnya sebuah bahan ajar memiliki fungsi utama agar mahasiswa lebih mudah menacapai tujuan pembelajaran, seperti memahami konsep. Oleh karena itu, penting melihat faktor kemudahan bahan ajar untuk dipahami. Berdasarkan tujuan tersebut, aspek penggunaan bahasa yang baik memiliki skor 3,50 dan aspek cara penyajian yang baik memiliki skor 3,67 yang mana keduanya memiliki kriteria sangat valid.

Selain dari validitas yang dinilai oleh para ahli, proses pengembangan lembar kerja berbasis POE juga melalui uji terbatas. Uji terbatas ini dimaksudkan untuk melihat kebergunaan produk yang dikembangkan. Uji terbatas dilakukan pada kelompok kecil yakni pada 25 mahasiswa yang sedang mengikuti perkuliahan Fisika Dasar 1. Uji terbatas ini merupakan bentuk implementasi awal lembar kerja mahasiswa berbasis POE, karena digunakan untuk mengajarkan topik fluida statis. Data diperoleh dengan memberikan angket respon kepada mahasiswa. Data respon mahasiswa ditunjukkan pada Tabel 2. 
Tabel 2. Data Respon Mahasiswa terhadap LKM Berbasis POE

\begin{tabular}{llcccc}
\hline No & Indikator Respon & \multicolumn{4}{c}{$\mathrm{N}(\%)$} \\
\cline { 3 - 5 } & & $\mathrm{SS}$ & $\mathrm{S}$ & $\mathrm{TS}$ & $\mathrm{STS}$ \\
\hline 1 & Instruksi yang ada dalam LKM berbasis POE mudah & 4 & 21 & 0 & 0 \\
& untuk saya pahami. & $(16,00)$ & $(84,00)$ & $(0,00)$ & $(0,00)$ \\
2 & Langkah-langkah yang ada dalam LKM berbasis POE & 7 & 18 & 0 & 0 \\
& mudah dipahami dan diikuti. & $(28,00)$ & $(72,00)$ & $(0,00)$ & $(0,00)$ \\
3 & Konten LKM berbasis POE ini mempermudah saya & 5 & 20 & 0 & 0 \\
& dalam memahami konsep fluida statis. & $(20,00)$ & $(80,00)$ & $(0,00)$ & $(0,00)$ \\
4 & Tampilan LKM berbasis POE ini menarik dan tidak & 2 & 23 & 0 & 0 \\
& membosankan. & $(8,00)$ & $(92,00)$ & $(0,00)$ & $(0,00)$ \\
5 & Jenis dan ukuran huruf dalam LKM berbasis POE ini & 18 & 7 & 0 & 0 \\
& dapat saya baca dengan baik. & $(72,00)$ & $(28,00)$ & $(0,00)$ & $(0,00)$ \\
6 & LKM berbasis POE ini tidak memuat kalimat-kalimat & 18 & 7 & 0 & 0 \\
& atau kata-kata yang sulit untuk dipahami. & $(72,00)$ & $(28,00)$ & $(0,00)$ & $(0,00)$ \\
Rata-Rata \% Respon & $36,00 \%$ & $64,00 \%$ & $0,00 \%$ & $0,00 \%$ \\
\hline
\end{tabular}

Berdasarkan Tabel 2 tampak bahwa seluruh mahasiswa memberikan respon positif terhadap Lembar Kerja Mahasiswa berbasis POE. Jumlah responden yang sangat setuju lebih besar dari responden yang setuju pada indikator 'jenis dan ukuran huruf dalam LKM berbasis POE ini dapat saya baca dengan baik', dan 'LKM berbasis POE ini tidak memuat kalimat-kalimat atau kata-kata yang sulit untuk dipahami', yakni sebesar 72,00\%. Berdasarkan data tersebut dapat disimpulakn bahwa mahasiswa merasa terbantu dengan adanya Lembar Kerja Mahasiswa berbasis POE ini. Berdasarkan nilai rata-rata persentase responden yang memberikan respon positif terhadap Lembar Kerja Mahasiswa berbasis POE, yakni 36,00\% responden sangat setuju dan $64,00 \%$ mahasiswa yang setuju maka dapat disimpulkan bahwa Lembar Kerja Mahasiswa berbasis POE layak digunakan untuk membantu pembelajaran mahasiswa. Temuan tersebut sejalan dengan hasil penelitian Mariyana et al (2018) yang menyatakan bahwa LKS berbasis POE yang dikembangkannya pada topik suhu dan kalor telah layak menurut expert judgement dan siswa dalam uji terbatas. Selain berdasarkan pendapat mahasiswa yang telah menggunakan LKM berbasis POE tersebut, penggunaan media pembelajaran seperti ini juga mempermudah dan dapat menjembatani mahasiswa untuk belajar lebih baik. Tidak hanya itu, dengan bantuan LKM berbasis POE ini mahasiswa dapat lebih mudah belajar fisika sehingga menumbuhkan sikap positif mahasiswa terhadap pembelajaran (Hardiyanti et al, 2018).
Kemampuan Berpikir Kritis Mahasiswa

Data berpikir kritis mahasiswa diperoleh dengan pemberian soal. Dalam penelitian ini, terdapat lima indikator kemampuan berpikir kritis mahasiswa yakni,
(1) menganalisis;
(2) menyitesis;

memecahkan masalah; (4) menyimpulkan; dan (5) mengevaluasi. Data kemampuan berpikir kritis mahasiswa dapat dilihat pada Tabel 3.

Tabel 3. Data Kemampuan Berpikir Kritis

\begin{tabular}{lccc}
\hline Indikator & $\%$ & $\begin{array}{l}\text { \% } \\
\text { total }\end{array}$ & Katergori \\
\hline Menganalisis & 72 & & \\
Menyitesis & 60 & & \\
$\begin{array}{l}\text { Memecahkan } \\
\text { masalah }\end{array}$ & 80 & 69,6 & $\begin{array}{c}\text { Berpikir } \\
\text { kritis }\end{array}$ \\
Menyimpulkan & 72 & & \\
Mengevaluasi & 64 & & \\
\hline
\end{tabular}

Berdasarkan Tabel 3 kemampuan mahasiswa yang baik adalah memecahkan masalah $(80 \%)$ sedangkan yang paling rendah adalah mensintesis $(60 \%)$. Hasil tersebut sesuai dengan penelitian (Anggraini et al, 2017). Hal ini diduga karena mahasiswa cenderung lebih menyukai soal-soal yang disajikan dalam bentuk hitungan, terutama jika soal yang dirancang dapat diselesaikan dengan sekedar plug and chug. Mahasiswa akan sulit menyelesaikan soal jika melibatkan banyak konsep. Seperti soal-soal yang menuntuk mahasiswa untuk menyintesis.

Berdasarkan hasil implementasi yang dilaksanakan sudah cukup menunjukkan 
kebergunaan Lembar Kerja Mahasiswa berbasis POE dalam perkuliahan fluida statis. Kendati demikian, berdasarkan evaluasi penggunaan Lembar Kerja Mahasiswa berbasis POE ini masih perlu adanya penyempurnaan konten. Hal tersebut berupa perbaikan gambar-gambar agar lebih membantu mahasiswa dalam memahami konsep Fluida Statis secara lebih baik.

Pada dasarnya berpikir kritis merepresentasikan salah satu aspek penting yang harus dikembangkan untuk mengasah kemampuan memecahkan permasalahan dalam kehidupan sehari-hari (Erceg et al, 2013). Telah banyak definisi dan ide terkait karakterisasi perpikir kritis (Pithers \& Soden, 2000; Zhang, 2003). Telah ratusan tahun kemampuan berpikir kritis sudah menjadi fokus penelitian oleh saintis, dan semua individu bekerja dalam ranah tertentu selalu memiliki rentetan kemampuan berpikir dengan kemampuan berpikir kritis sebagai dasar (Thompson, 2011). Bahkan kemampuan berpikir kritis menjadi salah satu tuntutan kemampuan yang harus dikuasai oleh siswa atau pun mahasiswa pada era ini.

\section{Simpulan}

Berdasarkan hasil dan pembahasan yang telah dipaparkan dapat disimpulkan bahwa pengembangan Lembar Kerja Mahasiswa berbasis POE ini telah mencapai tahapan evaluasi. Berdasarkan hasil validasi para ahli diperoleh bahwa Lembar Kerja Mahasiswa berbasis POE ini sangat valid. Selain itu, hasil respon mahasiswa pengguna memberikan respon positif terhadap produk, yakni sebanyak $36,00 \%$ mahasiswa sangat setuju dan $64,00 \%$ mahasiswa setuju terhadap kelayakan Lembar Kerja Mahasiswa berbasis POE. Skor kemampuan berpikir kritis mahasiswa sebesar 69,6 menunjukkan bahwa mahasiswa berada dalam kategori berpikir kritis. Penelitian terbatas pada tahapan mengevaluasi produk yang telah dikembangkan. Bagi peneliti kedepannya dapat mengimplementasikan Lembar Kerja Mahasiswa berbasis POE dan menguji efektivitasnya melalui penelitian eksperimen agar lebih teruji.

\section{Daftar Pustaka}

Akbar, S. (2013). Instrumen Perangkat Pembelajaran. Bandung: PT Remaja Rosdakarya.
Aldobie, N. (2015). ADDIE Model. Merican International Journal of Contemporary Research, 5(6), 68-72.

Anggraini, R., Wahyuni, S., \& Lesmono, A. D. (2016). Pengembangan Lembar Kerja Siswa (LKS) Berbasis Keterampilan Proses Di Sman 4 Jember. Jurnal Pembelajaran Fisika, 4, 350-357.

Anggraini, S. A. P., Lesmono, A. D., \& Handono, S. (2017). Pengembangan Lembar Kerja Siswa (LKS) Fisika Berbasis POE Materi Gerak Harmonis Sederhana Di MAN. In Seminar Nasional Pendidikan Fisika 2017 (Vol. 2, pp. 1-6). Jember: Universitas Negeri Jember.

Bakri, F., Rasyid, R., \& Mulyaningsih, R. D. A. (2015). Pengembangan Modul Fisika Berbasis Visual untuk Sekolah Menengah Atas ( SMA ). Jurnal Penelitian \& Pengembangan Pendidikan Fisika, 1(2), 67-74.

Başer, M. (2006). Effect of conceptual change oriented instruction on remediation of students 'misconceptions related to heat and temperature concepts. Journal of Maltese Education Research, 4(1), 64-79. https://doi.org/10.1061/(ASCE)07339410(1991)117

Clement, J. (1982). Students' preconceptions in introductory mechanics. American Journal of Physics, 50(1), 66-71. https://doi.org/10.1119/1.12989

Docktor, J. L., \& Mestre, J. P. (2014). A Synthesis of Discipline-Based Education Research in Physics. Physical Review Special Topic - Physics Education Research, 1-148.

Erceg, N., Aviani, I., \& Mešić, V. (2013). Probing stuDents' critical thinking processes by presenting ill-Defined physics problems. Revista Mexicana de Fisica $\quad E, \quad 59(1), \quad$ 65-76. https://doi.org/10.1117/12.903323

Fitriastuti, N., Sulisworo, D., \& Ishafit. (2018). Pengembangan Modul Pembelajaran Fisika Berbasis Scientific Approach pada Materi Suhu dan Perpindahannya Siswa Kelas VII SMP. Jurnal Wahana Pendidikan Fisika, 3(1), 103-107. 
Fitriyati, Kurniawan, E. S., \& Ngazizah, N. (2013). Pengembangan LKS Fisika SMA Kelas X Semester II dengan Website Online Berbasis Contextual Teaching Learning, 3(1), 7-11.

Hammer, D. (1996). More than misconceptions: Multiple perspectives on student knowledge and reasoning, and an appropriate role for education research. American Journal of Physics, 64(10), 1316-1325.

https://doi.org/10.1119/1.18376

Hammer, D. (2000). Student resources for learning introductory physics. American Journal of Physics, 68(S1), S52-S59. https://doi.org/10.1119/1.19520

Hardiyanti, K., Astalini, \& Kurniawan, D. A. (2018). Sikap Siswa terhadap Mata Pelajaran Fisika Di SMA Negeri 5 Muaro Jambi. Jurnal EduFisika, 3(2), 1-12.

Hidayah, A., \& Yuberti. (2018). Pengaruh model pembelajaran POE (PredictObserve-Explain) terhadap keterampilan proses belajar fisika siswa pokok bahasan suhu dan kalor. Indonesian Journal of Science and Mathematics Education, 01(1), 21-27.

Maharani, D., Prihandono, T., \& Lesmono, A. D. (2015). Pengembangan LKS Multirepresentasi Berbasis Pemecahan Masalah pada Pembelajaran Fisika Di SMA. Jurnal Pembelajaran Fisika, 4(3), 236-242.

Marcella, Z., Susanti, N., \& Dani, R. (2018). Analisis Hambatan Pelaksanaan Praktikum IPA Terpadu Di SMPN 17 dan SMPN 19 Kota Jambi. Jurnal EduFisika, $3(2), 42-48$.

Mariyana, S., Maison, \& Syarkowi, A. (2018). Pengembangan Lembar Kerja Siswa (LKS) Berbasis POE (Predict, Observe, Explain) pada Materi Suhu dan Kalor. Jurnal EduFisika, 3(1), 96-108.

Minogue, J., \& Borland, D. (2016). Investigating Students' Ideas About Buoyancy and the Influence of Haptic Feedback. Journal of Science Education and Technology, 25(2), 187-202. https://doi.org/10.1007/s10956-015-95851
Miswadi, S. S., Wijayati, N., \& Farikhati, L. I. (2010). Pengaruh Penggunaan Metode Preview, Question, Read, Summarize , and Test Melalui Pendekatan Contextual Teaching and Learning Terhadap Hasil Belajar Kimia Siswa SMA. Jurnal Inovasi Pendidikan Kimia, 4(1), 557-565.

Nurhudayah, M., Lesmono, A. D., \& Sabiki. (2016). Penerapan Model Inkuiri Terbimbing (Guided Inquiry) dalam Pembelajaran Fisika SMA Di Jember (Studi pada Keterampilan Proses Sains dan Keterampilan Berpikir Kritis). Jurnal Pembelajaran Fisika, 5(1), 82-88.

Pithers, R. T., \& Soden, R. (2000). Critical thinking in education: A review. Educational Research, 42(3), 237-249. https://doi.org/10.1080/001318800440579

Rahmat, M., Muhardjito, M., \& Zulaikah, S. (2014). Kemampuan Pemecahan Masalah Melalui Strategi Pembelajaran Thinking Aloud Pair Problem Solving Siswa Kelas X SMA. Jurnal Fisika Indonesia, 18(54), 108-112. Retrieved from http://pdmmipa.ugm.ac.id/ojs/index.php/jfi/article/vi ew/898/0

Riduwan. (2008). Dasar-Dasar Statistika. Bandung: Alfabeta. Bandung: Alfabeta.

Rivaldo, L., Taqwa, M. R. A., \& Taurusi, T. (2018). Resources Siswa SMA tentang Konsep Gaya Archimedes. Jurnal Pendidikan Fisika Universitas Muhammadiyah Makassar, 6(3), 251-258. Retrieved from http://journal.unismuh.ac.id/index.php/jpf/ issue/view/114/showToc

Rozana, T., Jufrida, \& Basuki, F. R. (2018). Penerapan model pembelajaran POE untuk meningkatkan keterampilan proses sains kelas XI SMAN 11 Jambi. Jurnal EduFisika, 3(2), 66-80.

Taqwa, M. R. A., \& Faizah, R. (2016). Perlunya Program Resitasi untuk Meningkatkan Kemampuan Mahasiswa dalam Memahami Konsep Gaya dan Gerak. Pros. Semnas Pend. IPA Pascasarjana UM, 12(1), 365-372.

Taqwa, M. R. A., Hidayat, A., \& Supoto. (2017). Konsistensi Pemahaman Konsep Kecepatan dalam Berbagai Representasi. 
Jurnal Riset \& Kajian Pendidikan Fisika, 4(1), 31-39. https://doi.org/http://dx.doi.org/10.12928/j rkpf.v4i1.6469

Taqwa, M. R. A., Hidayat, A., \& Sutopo. (2017). Deskripsi Penggunaan Program Resitasi dalam Meningkatkan Kemampuan Membangun Free-Body Diagrams ( FBDs ). Jurnal Pendidikan Fisika Tadulako, 5(1), 52-58. https://doi.org/10.22487/j25805924.2017. v5.i1.8411

Taqwa, M. R. A., \& Pilendia, D. (2018). Kekeliruan Memahami Konsep Gaya, Apakah Pasti Miskonsepsi? Jurnal Inovasi Pendidikan Fisika Dan Integrasinya, 01(02), 1-12.

Taqwa, M. R. A., Priyadi, R., \& Rivaldo, L. (2019). Pemahaman Konsep Suhu dan Kalor Mahasiswa Calon Guru. Jurnal Pendidikan Fisika, 7(1), 56-67.
Thompson, C. (2011). Critical thinking across the curriculum: Process over output. International Journal of Humanities and Social Science, 1(9), 1-7. https://doi.org/10.1007/s11245-016-94014

Wahyuni, S. (2015). Pengembangan Bahan Ajar IPA untuk Meningkatkan Kemampuan Berpikir Kritis Siswa SMP. Jurnal Materi Dan Pembelajaran Fisika, $5(2), 47-52$.

Zhang, L.-F. (2003). Contribution of Thinking Styles to Critical Thinking Dispositions. The Journal of Psychology, 137(6), 517544.

https://doi.org/10.16309/j.cnki.issn.10071776.2003.03.004 